\title{
Un monde plus juste et durable est possible... comment pouvons-nous le créer?
}

Constanza Parra

\section{(2) OpenEdition}

1 Journals

Édition électronique

URL : http://journals.openedition.org/developpementdurable/12097

DOI : 10.4000/developpementdurable.12097

ISSN : 1772-9971

Éditeur

Association DD\&T

\section{Référence électronique}

Constanza Parra, « Un monde plus juste et durable est possible... comment pouvons-nous le créer? », Développement durable et territoires [En ligne], Vol. 9, $n^{\circ} 1$ | Mars 2018, mis en ligne le 30 mars 2018, consulté le 24 septembre 2020. URL : http://journals.openedition.org/developpementdurable/12097 ; DOI : https://doi.org/10.4000/developpementdurable.12097

Ce document a été généré automatiquement le 24 septembre 2020.

Développement Durable et Territoires est mis à disposition selon les termes de la licence Creative Commons Attribution - Pas d'Utilisation Commerciale 4.0 International. 


\title{
Un monde plus juste et durable est possible... comment pouvons-nous le créer?
}

\author{
Constanza Parra
}

1 Cet éditorial a été rédigé au moment où l'hémisphère nord commence à laisser derrière lui un long et froid hiver afin d'accueillir les premiers rayons tièdes du soleil annonçant le printemps. Par nos fenêtres et lors de nos promenades du dimanche, nous devenons les témoins de l'apparition des premiers crocus dans les parcs de la ville, des bouquets de tulipes dans les marchés et aussi de la floraison des amandiers couvrant la Méditerranée avec des milliers de fleurs blanches et roses. Face à cette transformation que nous éprouvons chaque année lors des mois de mars et d'avril, nos sens et nos perceptions sont stimulés par les différentes formes, couleurs, parfums et tonalités que la nature prend lors du printemps. De ce fait, nos imaginaires et notre état d'esprit trouvent, très souvent, un nouveau souffle qui nous soutiendra dans notre vie quotidienne jusqu'aux vacances d'été. Cet éditorial est une invitation à mobiliser cette inspiration printanière pour repenser la relation entre durabilité, développement et justice socio-environnementale. Comme le titre de cet éditorial l'annonce, je crois qu'un monde plus juste et durable est possible... néanmoins la question des chemins conduisant à cette aspiration attend encore une réponse plus convaincante.

Le point de départ optimiste annoncé dans cet éditorial n'implique pas une démarche condamnée à fermer les yeux sur les nombreuses injustices : des violations des droits de l'homme, à la longue liste de catastrophes socio-écologiques qui sont exposées chaque jour dans les journaux et dans d'autres médias. Il n'est pas non plus dans notre objectif d'insister sur notre frustration personnelle et collective, ou sur la colère, qui découlent de ces multiples injustices et expressions d'une absence de durabilité. Il est cependant difficile, voire impossible, de les oublier ou de les laisser de côté. En revanche, notre intention aujourd'hui est plutôt d'inviter les lecteurs de la revue Développement Durable et Territoires à réfléchir, une fois de plus et peut-être à partir d'un angle différent, à ce 
que l'on pourrait appeler «une ambition de durabilité socio-écologique possible mais encore inachevée».

3 Compte tenu des défis et problèmes de durabilité multiples qui remplissent les pages de nos journaux, inspirent nos travaux de recherche et interviennent dans les processus de décision sociopolitique des sociétés contemporaines, cet éditorial prend la forme d'une invitation, adressée aux partisans et aux experts du développement durable, à participer à la rédaction "d'une liste de printemps", composée de réflexions, idées, expériences et alternatives pour amplifier la mise en œuvre d'une ambition de durabilité socio-écologique en construction. Je me permets de commencer aujourd'hui cette liste avec les trois propositions suivantes :

4 La première proposition évoque l'appel de Marris (2015) pour une attitude d'humilité des humains dans la soi-disant époque de l'anthropocène (expression oh combien controversée). Dans ses mots, "quand ceux qui parlent de l'anthropocène disent "les humains contrôlent la planète", ils ne signifient pas que les humains sont au contrôle. Ils signifient simplement que nous sommes devenus l'un des principaux moteurs du changement. Et c'est indiscutablement [et malheureusement] vrai " (Marris, 2015 : 44). Ainsi, pour Marris (2015), parler de la façon dont les humains contrôlent ou dominent la planète n'est pas seulement une erreur mais aussi de l'arrogance.

5 La deuxième proposition fait référence à la pluralité des valeurs sous-jacentes à une démarche de durabilité. Il s'agit notamment d'un développement durable fondé sur un rapport de dignité entre nature et société, au sein duquel la nature est respectée pour sa valeur intrinsèque et où l'on souligne toutes ces valeurs et droits humains fondamentaux qui se trouvent à la base d'une reproduction socialement durable de notre vivre ensemble (Parra, 2018).

6 Enfin, la troisième proposition est un appel à jeter un regard plus profond sur ceux qui aujourd'hui sont en train de travailler et d'investir de l'énergie dans la construction d'une société meilleure. D'un côté, on fait référence aux communautés, groupes sociaux, individus et leaders qui se sont engagés dans l'imagination et la matérialisation de formes de vie plus durables fondées sur des principes de solidarité, gentillesse, démocratie et équité (Manier, 2012; Courrier International, 2009). D'un autre côté, on fait référence à ces politiques publiques, menées par les gouvernements et par d'autres institutions qui sont favorables à ces types de groupes et initiatives, et en conséquence sont en train de les soutenir et de les encourager (to empower) avec des programmes et politiques publiques progressistes et socialement innovants.

7 Voici donc un début de liste pour continuer à réfléchir, sous les rayons du soleil de ce printemps qui commence, aux possibilités d'une durabilité socialement engagée en faveur d'une vie et d'un monde plus juste, démocratique et durable. 


\section{BIBLIOGRAPHIE}

Courrier International, 2009, « Changer le modèle face à la crise : la vie meilleure, mode d'emploi », Hors-Série.

Manier B., 2012, Un Million de Révolutions Tranquilles, Paris, Éditions Les Liens qui Libèrent, 360 p.

Marris E., 2015, « Humility in the Anthropocene », in B. A. Minteer et S. J. Pyne (eds), After Preservation: Saving American Nature in the Age of Humans, University of Chicago Press, p. 41-49.

Parra C., 2018, « What can culture in and for sustainable development learn from protected areas? » in I. Birkeland, R. Burton, C. Parra et K. Siivonen (eds.), Cultural sustainability and the nature-culture interface: Livelihoods, policies and methodologies, Routledge, p. 49-65.

\section{AUTEUR}

\section{CONSTANZA PARRA}

Constanza Parra est Assistant Professor au Département des Sciences de la Terre et de l'Environnement de l'Université de Louvain et s'intéresse à la façon dont les sociétés interagissent avec l'environnement et aux défis contemporains en matière de développement durable. Ses recherches portent sur la durabilité sociale, les rapports nature-culture, la justice environnementale et l'innovation sociale dans la gouvernance des systèmes socioécologiques. Ses projets de recherche en cours, en Europe et en Amérique Latine, abordent des sujets tels que les espaces naturels protégés, la mise en œuvre des paiements pour services environnementaux et des mécanismes REDD+, les catastrophes, les enjeux du land grabbing et les communs territoriaux. 